\title{
Epidemiological Assessment of Testosterone Levels in Women Population: A Factorial Analysis of Cell Proliferation
}

Victor Eshu Okpashi ${ }^{\star}$, Bonaventure Chukwunonso Obi, Innocent Okagu and Prince Odilichukwu Okoroafor

Department of Biochemistry, University of Nigeria, Nsukka, Nigeria

"Corresponding author: Victor Eshu Okpashi, Department of Biochemistry, University of Nigeria, Nsukka, Nigeria, Tel: +2348037636808; E-mail: vic2reshu@gmail.com

Received date: March 10, 2018; Accepted date: April 24, 2018; Published date: May 01, 2018

Copyright: (C) 2018 Okpashi VE, et al. This is an open-access article distributed under the terms of the Creative Commons Attribution License, which permits unrestricted use, distribution and reproduction in any medium, provided the original author and source are credited.

\begin{abstract}
In women, testosterone is produced in the ovaries, adrenal glands, and fat cells. Women may produce much or little of testosterone. Excess Testosterones and deficiencies are among the common hormonal disorders in women. Testosterone in women plays a role in the hormonal cascade that kick-starts puberty and stimulates hair growth. In adult women, testosterone is necessary for estrogen synthesis and have played a key role in the prevention of bone loss, sexual desire, and satisfaction. Testosterone can affect the breast and it is well implicated in testosterone therapy for women. The need to bring about shreds of evidence linking specific human health effect due to testosterone imbalance in women for the assessment of reproduction insufficiency was the purpose of this investigation. Results from clinical observations and epidemiological studies implicate testosterone imbalance as a significant treatment of public health. A total of 186 women of Eket Community in Akwa Ibom State, Nigeria, were purposively and disproportionately selected, using simplified sample size formula. Blood serums were prepared using the blood obtained from donors. The in vitro assay of the testosterone and sex hormone binding globulin was achieved using enzyme-linked immunosorbent assay technique. The ratio of sex hormone binding globulin to testosterone was calculated and free testosterone was obtained. The in vitro hormonal quantification showed that 38 $(20 \%)$ of women had testosterone level above the reference range $-4.42-32.02 \mathrm{ng} / \mathrm{ml} / \mathrm{mmol} / \mathrm{L}$, while $148(80 \%) \mathrm{had}$ low testosterone level. This showed that a fraction of women in Eket community with high levels of a form of testosterone called "free" testosterone may have polycystic ovary syndrome (PCOS), characterized by irregular or absent of menstrual periods, infertility, blood sugar disorders (pre-diabetes and type 2 diabetes), and, in some cases, symptoms such as acne and excess hair growth may set in.
\end{abstract}

Keywords: Androgen; Women; Testosterone; Free testosterone; Sex hormone binding globulin epidemiology

\section{Introduction}

The prevalence of reproductive abnormality in women is due to elevated testosterone, an antagonist of estrogen dominance and sometimes elevated steroid sex hormone binding globulin (SHBG), which makes it possible for estrogen to dominate in the cells to exert epithelia cells proliferation. The balance between stimulatory effects of the estrogens and inhibitory effects of the testosterone is the critical factor that regulates mammary cell proliferation both in normal and in cancer tissues [1]. Several epidemiological studies have examined the correlation between circulating testosterone and the risk for breast cancer. Testosterones play a role in normal breast physiology. Androgen receptor (AR) signaling is recognized as an important therapy of breast carcinogenesis. The frequency of AR expression in breast cancer makes it an attractive therapeutic target, while deregulation of this hormone poses a health risk. A major limitation was that the androgen assays used were developed primarily to measure the higher levels found in men and lack reliability in the low ranges found in normal women [2]. Testosterone levels revealed considerable daily variability, though some epidemiological data are based on a single blood sample assay that is collected at non-standard times. Another concern is using serum testosterone levels to determine androgenic effects at the tissue level where circulating testosterone is firmly bound to sex hormone binding globulin (SHBG), while the free hormone is bioactive [3]. SHBG and total testosterone levels differ greatly based on genetic or epigenetic grounds, metabolic and endocrine influences [3]. It has been accepted that measuring free or bio-available testosterone predicts androgenic effects more accurately than total testosterone levels [2]. It is purveyed that most androgenic activity in women originates from the peripheral conversion of precursors such as estrogens into androgens within the cells of target tissues, and this activity cannot be detected by measurement of circulating androgens only [4]. In a recent study about the levels of testosterone in saliva, they were significantly fewer patients with breast cancer compared to controls and these differences were profound in postmenopausal women [5]. Though breast cancer patients, when compared to controls, revealed androgen insufficiency, while a relative imbalance of sex steroid hormones favors estrogens.

Several studies have been carried out in this area, but none has disconnected the risk associated with increased estradiol levels from the testosterone, and since testosterone are the obligate precursors for estradiol synthesis, a major confounding factor in assessing the role of testosterone independently of known cancer-promoting estrogens effect is important. In line with these observations, a recent study by Schmitt et al. [6] concluded that increased breast cancer risk with increasing body mass index among postmenopausal women is due to increase in estrogens. The association of testosterone with breast cancer risk did not persist after adjustment of estrone [7]. This probably gave further proof that estrogens are strongly associated with the risk of cancer and infertility. Some authors conclude that conversion of testosterone to estrogens by aromatase particularly estradiol is required to exert a mitogenic response [8]. These results suggest that the contribution of testosterone to breast cancer risk is 
largely through their role as substrates for estrogen production. Other studies have found no association between testosterone and breast cancer [9]. Observations expressed the difficulty in separating direct effects of circulating testosterone from its potential to be aromatized into estradiol. Testosterones are indeed protective against estrogeninduced mammary proliferation at certain levels. Additionally, testosterone treatment significantly reduced mammary epithelial estrogen receptor expression, thus suggesting a potential mechanism for the growth inhibitory effect [10]. Some researchers have found that treatment of intact cycling monkeys with the $\mathrm{AR}$ antagonist (flutamide) resulted in a significant increase in mammary epithelial proliferation [11], this added to the evidence that endogenous testosterone can limit mammary proliferation and cancer risk. One study on primates also suggests that inclusion of testosterone with estrogen/progesterone may counteract breast cell proliferation [12].

This research was set out to establish that free testosterone level in women is a potent causation of mammary cell proliferation since testosterone is aromatized to estrogens.

\section{Materials and Methods}

\section{Ethical approval}

Ethical approval was obtained from the Ministry of Health, Akwa Ibom State, Nigeria. A letter of approval was granted 18 September 2015 and issued 28 September 2015.

\section{Collection of blood serum}

Blood samples from individuals of Eket community were based on 186 samples, using a simplified sample size formula, (equation 1 in Online sample Size Calculator by Raosoft, Inc.) [12]. The confidence level was $95 \%$, the margin of error or confidence interval was $5 \%$, total population size was 172,856 and percentage population coverage $50 \%$.

\section{Collection of blood samples}

A convenient vein was located on the left of the volunteer's hand; a tourniquet was tied to the hand above the elbow. The point of venipuncture was swooped with a wet cotton wool impregnated with methylated spirit. The needle was assembled with the syringes after wearing hand gloves. The vein was penetrated to draw $2 \mathrm{ml}$ of blood, and a dry cotton wool was applied at the open point to inhibit bleeding. The collected blood was emptied into plain sample bottles and allows for about 1-hour clotting. The used needle was discarded into a disposable box. After blood clotting, it was centrifuged at $2000 \mathrm{~g}$ rpm for 10 minutes. The serum was collected as supernatant using disposable Pasteur pipette and refrigerated at $-20^{\circ} \mathrm{C}$ before taking with an ice pack for hormonal assay.

\section{Preparation of reagents}

All reagents were allowed to reach room temperature $\left(18-25^{\circ} \mathrm{C}\right)$ before use. Reagents were mixed by gentle inversion or swirling prior to use and foaming was avoided. Samples with expected testosterone concentrations over $18 \mathrm{ng} / \mathrm{ml}$ were quantitated by dilution with the diluent provided by the Diagnostic Automation Inc.

\section{Test principle for sex hormone binding globulin and testosterone}

The enzyme-linked immunosorbent assay (ELISA) is based on the sandwich principle. The microtiter wells are coated with a monoclonal [mouse] antibody directed towards a unique antigenic site of the SHBG and TT (testosterone) molecule. An aliquot of a sample containing endogenous SHBG or TT is incubated in the coated well. After a washing step, enzyme conjugate is added, which is a monoclonal anti-SHBG or TT antibody conjugated with horseradish peroxidase. After incubation, the unbound conjugate is washed off. The amount of bound peroxidase is proportional to the concentration of SHBG or TT in the sample.

\section{Chemicals}

All chemicals used for this investigation are reagents of grade or higher, purchased from Reporter Assay Systems (AccuDiag ${ }^{m i n}$ ELISA) Diagnostic Automation/Cortez diagnostics Inc. 23961 Craftsman Road, Suite D/E/F Calabasas, CA 91302, USA. Venipuncture was carried out by licensed Phlebotomist.

\section{Statistical analysis}

Investigations on testosterone and sex hormone binding globulin levels were carried out using enzyme-linked immunosorbent assay and concentrations of testosterone and SHBG was interpolated by Spline and Lowess method using the Spline Curve via graph prism version 6.5.

\section{Results}

Concentrations of testosterone were interpolated using linear regression. Graph-Pad prism version 6.02 was used. The absorbance was read with respect to their optical density at $450 \mathrm{~nm}$ in a microplate reader. The plot depicts a linear correlation of the absorbance. The mean absorbance value (optical density $450 \mathrm{~nm}$ ) for each set of reference standards, controls and samples were calculated. The standard curve was constructed by plotting the mean absorbance obtained for each reference standard against its concentration in $\mathrm{ng} / \mathrm{ml}$ on linear-linear graph paper, with absorbance on the vertical (y) axis and concentration on the horizontal (x) axis. By using the mean absorbance value for each sample, the corresponding concentration of testosterone $\mathrm{ng} / \mathrm{ml}$ from the standard curve was determined. Values obtained for diluted samples were further converted by applying the appropriate dilution factor in the calculations sees the standard curve in Figures 1 and 2.

The average absorbance values for each of standards, controls, and samples were calculated. By using semi-logarithmic graph paper, a standard curve was constructed by plotting the mean absorbance obtained from each standard against its concentration with absorbance value on the vertical $(\mathrm{Y})$ axis and concentration on the horizontal (X) axis. Using the mean absorbance value for each sample, the corresponding concentration from the standard curve was determined. The 1-hour of the samples was read directly from this standard curve. Samples with concentrations higher than that of the highest standard have to be further diluted or reported as $>260 \mathrm{nmol} / \mathrm{l}$. For the calculation of the concentrations, this dilution factor was taken into account. 
Citation: Okpashi VE, Obi BC, Okagu I, Okoroafor PO (2018) Epidemiological Assessment of Testosterone Levels in Women Population: A

Page 3 of 8

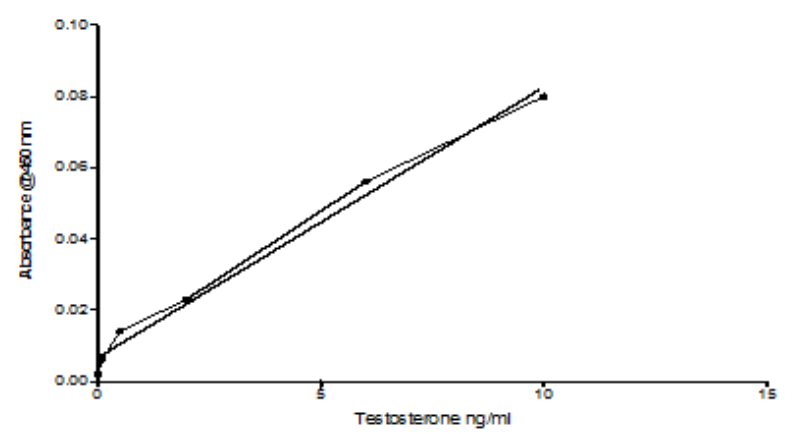

Figure 1: Calibration curve for testosterone.

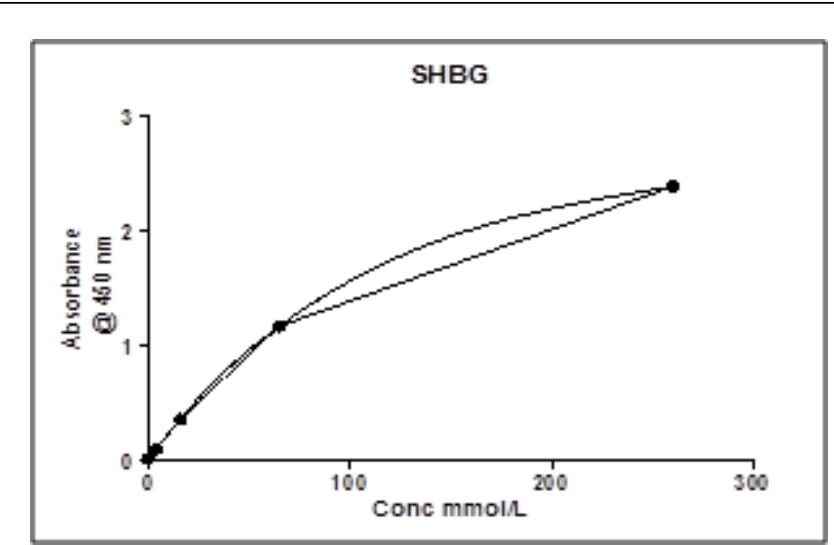

Figure 2: Curve of sex hormone binding globulin.

\begin{tabular}{|c|c|c|c|c|c|c|c|c|c|}
\hline Lab No. & Age & T. concentration $\mathrm{ng} / \mathrm{mL}$ & $\begin{array}{l}\text { SHBG } \\
\mathrm{mmol} / \mathrm{L}\end{array}$ & Free. T & Lab. No. & Age & $\begin{array}{c}\text { T. concentration } \\
\mathrm{ng} / \mathrm{mL}\end{array}$ & $\begin{array}{l}\text { SHBG } \\
\text { Mmol/L }\end{array}$ & $\begin{array}{c}\text { Free.T. mmol/l/ } \\
\mathrm{ng} / \mathrm{ml}\end{array}$ \\
\hline 1 & 36 & 2.82 & 30.2 & $10.71^{*}$ & 41 & 28 & 8.99 & 59.4 & 6.6 \\
\hline 2 & 38 & 2.29 & 110.5 & $48.25^{\star *}$ & 42 & 37 & 2.6 & 11 & 4.23 \\
\hline 3 & 28 & 1.63 & 43 & $26.38^{* *}$ & 43 & 45 & 1.91 & 16.3 & 8.53 \\
\hline 4 & 33 & 2.16 & 12.1 & 5.6 & 44 & 60 & 12.55 & 134 & $10.67^{* *}$ \\
\hline 5 & 30 & 2.95 & 4 & 1.36 & 45 & 45 & 9.85 & 78.2 & 7.93 \\
\hline 6 & 28 & 1.76 & 34.9 & $19.83^{* *}$ & 46 & 66 & 13.9 & 110 & 7.91 \\
\hline 7 & 26 & 2.68 & 38.1 & $14.22^{* *}$ & 47 & 29 & 7.99 & 45.9 & 5.74 \\
\hline 8 & 30 & 2.03 & 29.5 & $14.53^{* *}$ & 48 & 56 & 15.67 & 153.4 & 9.79 \\
\hline 9 & 33 & 1.9 & 25.6 & $13.47^{* *}$ & 49 & 74 & 9.42 & 97.8 & $10.38^{* *}$ \\
\hline 10 & 29 & 2.55 & 11.3 & 4.43 & 50 & 45 & 5.82 & 30.5 & 5.24 \\
\hline 11 & 44 & 2.42 & 30.6 & 12.64 & 51 & 39 & 12.56 & 78.9 & 6.28 \\
\hline 12 & 28 & 2.16 & 153 & $70.83^{* *}$ & 52 & 38 & 13.85 & 107.2 & 7.74 \\
\hline 13 & 31 & 1.9 & 11 & 5.79 & 53 & 39 & 22 & 88.5 & 4.02 \\
\hline 14 & 34 & 1.76 & 23.5 & $13.35^{\star *}$ & 54 & 27 & 7.17 & 30.4 & 4.23 \\
\hline 15 & 40 & 2.16 & 15.6 & 7.22 & 55 & 44 & 11.9 & 98.9 & 8.31 \\
\hline 16 & 30 & 22.34 & 162.1 & 7.25 & 56 & 49 & 9.66 & 69.9 & 7.23 \\
\hline 17 & 34 & 2.16 & 34.7 & $16.06^{* *}$ & 57 & 39 & 1.9 & 23.9 & $12.57^{\star *}$ \\
\hline 18 & 37 & 7.72 & 67.9 & 8.79 & 58 & 35 & 1.55 & 9.3 & 6 \\
\hline 19 & 30 & 3.1 & 15.9 & 5.12 & 59 & 60 & 4.18 & 15.5 & 3.71 \\
\hline 20 & 36 & 10.9 & 79.8 & 7.32 & 60 & 26 & 12.67 & 133 & $10.49^{* *}$ \\
\hline 21 & 45 & 1.8 & 11.9 & 6.61 & 61 & 39 & 13.34 & 80 & 5.99 \\
\hline 22 & 44 & 5.11 & 12.5 & 2.44 & 62 & 26 & 8.1 & 98.9 & $12.20^{* *}$ \\
\hline 23 & 33 & 4.97 & 38.9 & 7.82 & 63 & 27 & 9.11 & 67.3 & 7.39 \\
\hline
\end{tabular}


Citation: Okpashi VE, Obi BC, Okagu I, Okoroafor PO (2018) Epidemiological Assessment of Testosterone Levels in Women Population: A Factorial Analysis of Cell Proliferation. Biol Med (Aligarh) 10: 440. doi:10.4172/0974-8369.1000440

Page 4 of 8

\begin{tabular}{|l|l|l|l|l|l|l|l|l|l|}
\hline 24 & 34 & 2.7 & 16.6 & 6.14 & 64 & 39 & 12.77 & 110 & 8.61 \\
\hline 25 & 32 & 1.9 & 6.9 & 3.63 & 65 & 56 & 5.81 & 23 & 3.95 \\
\hline 26 & 23 & 10 & 37.6 & 3.76 & 66 & 58 & 1.33 & 9.9 & 7.44 \\
\hline 27 & 34 & 9.55 & 40.5 & 4.24 & 67 & 35 & 6.88 & 25.5 & 3.7 \\
\hline 28 & 23 & 2.36 & 15.5 & 6.56 & 68 & 47 & 2.15 & 13 & 6.04 \\
\hline 29 & 26 & 1.72 & 12.2 & 7.09 & 69 & 46 & 10.89 & 67.8 & 6.22 \\
\hline 30 & 29 & 3.89 & 37.9 & $9.74^{* *}$ & 70 & 38 & 10.98 & 76.8 & 6.99 \\
\hline 31 & 30 & 4.43 & 18.4 & 4.15 & 71 & 37 & 8.23 & 56.2 & 6.82 \\
\hline 32 & 40 & 9.11 & 97.6 & $10.71^{* *}$ & 72 & 31 & 4.35 & 12.9 & 2.96 \\
\hline 33 & 44 & 2.42 & 13.7 & 5.66 & 73 & 37 & 2.38 & 18.9 & 7.94 \\
\hline 34 & 58 & 1.23 & 9.9 & 8.04 & 74 & 41 & 9.9 & 45.9 & 4.63 \\
\hline 35 & 36 & 2.89 & 17.1 & 5.91 & 75 & 38 & 10.78 & 156 & $14.47^{* *}$ \\
\hline 36 & 46 & 7.19 & 35.9 & 4.99 & 76 & 50 & 12.45 & 165 & $13.25^{* *}$ \\
\hline 37 & 37 & 12.8 & 76.5 & 5.97 & 77 & 38 & 9.67 & 67 & 6.92 \\
\hline 38 & 33 & 2.16 & 23.5 & $10.87^{* *}$ & 78 & 59 & 10.45 & 98 & $9.38^{* *}$ \\
\hline 39 & 23 & 1.24 & 8 & 6.45 & 79 & 53 & 13.32 & 56.9 & 4.27 \\
\hline 40 & 22 & 10.23 & 37.3 & 3.64 & 80 & 56 & 10.89 & 78.9 & 7.24 \\
\hline
\end{tabular}

Table 1A: Testosterone and SHBG concentration in 186 women.

\begin{tabular}{|c|c|c|c|c|c|c|c|c|c|}
\hline Lab. No & Age & T. concentration $\mathbf{n g} / \mathrm{mL}$ & SHBG $\mathrm{mmol} / \mathrm{L}$ & Free $\mathrm{T}$. & Lab. No & Age & T. concentration $\mathrm{ng} / \mathrm{mL}$ & SHBG Mmol/L & $\begin{array}{c}\text { Free T. } \mathrm{mmol} / \mathrm{ll} / \\
\mathrm{ng} / \mathrm{ml}\end{array}$ \\
\hline 81 & 45 & 5.43 & 38.4 & 7.07 & 121 & 44 & 1.92 & 18 & $9.37^{* *}$ \\
\hline 82 & 44 & 2.44 & 18 & 7.37 & 122 & 39 & 2.89 & 12.5 & 4.32 \\
\hline 83 & 39 & 1.67 & 12.5 & 7.48 & 123 & 38 & 2.68 & 19.8 & 7.38 \\
\hline 84 & 38 & 1.55 & 19.8 & $12.77^{\star *}$ & 124 & 28 & 4.64 & 27.8 & 5.99 \\
\hline 85 & 28 & 6.78 & 27.8 & 4.1 & 125 & 49 & 8.98 & 79.9 & 8.89 \\
\hline 86 & 49 & 10.89 & 79.9 & 7.33 & 126 & 67 & 2.76 & 19.2 & 6.95 \\
\hline 87 & 67 & 2.98 & 19.2 & 6.44 & 127 & 45 & 1.2 & 9.2 & 7.66 \\
\hline 88 & 45 & 1.78 & 9.2 & 5.16 & 128 & 44 & 12 & 73.8 & 6.15 \\
\hline 89 & 44 & 9.98 & 73.8 & 7.39 & 129 & 51 & 7.86 & 46.9 & 5.96 \\
\hline 90 & 51 & 5.55 & 46.9 & 8.45 & 130 & 34 & 10.02 & 68.6 & 6.84 \\
\hline 91 & 34 & 12.61 & 68.6 & 5.44 & 131 & 35 & 1.4 & 8.5 & 6.07 \\
\hline 92 & 35 & 2.81 & 8.5 & 3.02 & 132 & 55 & 3.8 & 59.9 & $15.76^{\star \star}$ \\
\hline 93 & 55 & 7.9 & 59.9 & 7.58 & 133 & 63 & 7.8 & 38.9 & 4.39 \\
\hline 94 & 63 & 5.76 & 38.9 & 6.75 & 134 & 39 & 4.5 & 17 & 3.77 \\
\hline 95 & 39 & 1.7 & 17 & $10^{* *}$ & 135 & 39 & 4.9 & 17 & 3.46 \\
\hline 96 & 63 & 3.87 & 16.9 & 4.36 & 136 & 63 & 4.7 & 16.9 & 3.59 \\
\hline
\end{tabular}


Citation: Okpashi VE, Obi BC, Okagu I, Okoroafor PO (2018) Epidemiological Assessment of Testosterone Levels in Women Population: A

\begin{tabular}{|c|c|c|c|c|c|c|c|c|c|}
\hline 97 & 57 & 14.34 & 155.9 & $10.87^{* *}$ & 137 & 57 & 8.34 & 155.9 & $18.69^{* *}$ \\
\hline 98 & 27 & 10.39 & 167.1 & $16.08^{* *}$ & 138 & 27 & 13.64 & 167.1 & $12.25^{* *}$ \\
\hline 99 & 38 & 9.91 & 37.4 & 3.77 & 139 & 38 & 9.89 & 37.4 & 3.74 \\
\hline 100 & 44 & 9.14 & 79.9 & 10.71 & 140 & 44 & 5.5 & 79.9 & $14.52^{* *}$ \\
\hline 101 & 50 & 9.99 & 89.9 & 8.99 & 141 & 50 & 8.92 & 89.9 & 10.07 \\
\hline 102 & 28 & 8.5 & 66.8 & 7.85 & 142 & 28 & 9.22 & 66.8 & 7.24 \\
\hline 103 & 46 & 5.89 & 24.8 & 4.21 & 143 & 46 & 4.6 & 24.8 & 5.39 \\
\hline 104 & 56 & 10.2 & 50.9 & 4.99 & 144 & 56 & 8.99 & 50.9 & 5.66 \\
\hline 105 & 44 & 2.33 & 13.8 & 5.92 & 145 & 44 & 3.1 & 13.8 & 4.45 \\
\hline 106 & 55 & 2.6 & 17.9 & 6.88 & 146 & 55 & 2.67 & 17.9 & 6.7 \\
\hline 107 & 27 & 19.8 & 99.2 & 5.01 & 147 & 27 & 14.4 & 99.2 & 6.88 \\
\hline 108 & 26 & 2.12 & 33.9 & 15.99 & 148 & 26 & 4.67 & 33.9 & 7.25 \\
\hline 109 & 40 & 4.91 & 23.8 & 4.84 & 149 & 54 & 3.93 & 23.8 & 6.05 \\
\hline 110 & 47 & 10.98 & 89 & 8.1 & 150 & 65 & 2.12 & 24.7 & $11.65^{\star *}$ \\
\hline 111 & 33 & 21.15 & 86.5 & 4.08 & 151 & 45 & 2.88 & 19.7 & 6.84 \\
\hline 112 & 28 & 2.17 & 12 & 5.52 & 152 & 23 & 3.55 & 23.9 & 6.73 \\
\hline 113 & 33 & 12.67 & 115 & $9.07^{\star *}$ & 153 & 54 & 5.55 & 36.9 & 6.64 \\
\hline 114 & 25 & 2.17 & 13.3 & 6.12 & 154 & 43 & 4.45 & 39.8 & 8.94 \\
\hline 115 & 39 & 19.09 & 98.9 & 5.18 & 155 & 61 & 12 & 56.1 & 4.67 \\
\hline 116 & 35 & 1.18 & 13.55 & $11.48^{\star *}$ & 156 & 45 & 2.77 & 27.97 & $10.09^{* *}$ \\
\hline 117 & 45 & 7.67 & 56.5 & 7.36 & 157 & 44 & 4.16 & 34.9 & 8.38 \\
\hline 118 & 26 & 6.09 & 34 & 5.58 & 158 & 65 & 1.4 & 6.8 & 4.85 \\
\hline 119 & 54 & 4.27 & 45.5 & $10.65^{\star *}$ & 159 & 27 & 5.58 & 50.9 & $9.12^{\star *}$ \\
\hline 120 & 32 & 7.67 & 46.7 & 6.08 & 160 & 33 & 6.56 & 34.6 & 5.27 \\
\hline
\end{tabular}

Table 1B: Testosterone and SHBG concentration in 186 women.

\begin{tabular}{|l|l|l|l|l|}
\hline \multicolumn{1}{|c|}{ Lab. No. } & \multicolumn{1}{|c|}{ Age } & \multicolumn{1}{c|}{ SHBG (mmol/l) } & \multicolumn{1}{c|}{ Free T. (mmol/// $\mathbf{n g} / \mathbf{m l})$} \\
\hline 161 & 34 & 1.9 & 2.89 & 1.52 \\
\hline 162 & 43 & 3.3 & 13.5 & 4.09 \\
\hline 163 & 65 & 3.7 & 7.9 & 2.13 \\
\hline 164 & 56 & 8.3 & 27.8 & 3.34 \\
\hline 165 & 67 & 2.3 & 16.9 & 7.34 \\
\hline 166 & 60 & 1.2 & 19.3 & $16.08^{* *}$ \\
\hline 167 & 65 & 0.3 & 1.4 & 4.67 \\
\hline 168 & 54 & 2.1 & 3.1 & 1.47 \\
\hline 169 & 33 & 0.3 & 1.6 & 5.33 \\
\hline
\end{tabular}


Citation: Okpashi VE, Obi BC, Okagu I, Okoroafor PO (2018) Epidemiological Assessment of Testosterone Levels in Women Population: A Factorial Analysis of Cell Proliferation. Biol Med (Aligarh) 10: 440. doi:10.4172/0974-8369.1000440

Page 6 of 8

\begin{tabular}{|c|c|c|c|c|}
\hline 170 & 24 & 0.8 & 1.8 & 2.25 \\
\hline 171 & 31 & 9.2 & 28.9 & $9.2^{* \star}$ \\
\hline 172 & 30 & 9.3 & 29.3 & 3.15 \\
\hline 173 & 45 & 2.2 & 12 & 5.45 \\
\hline 174 & 55 & 2.9 & 21 & 7.24 \\
\hline 175 & 47 & 4.7 & 12 & 2.55 \\
\hline 176 & 49 & 8.4 & 19.4 & 2.3 \\
\hline 177 & 50 & 6.7 & 20 & 2.98 \\
\hline 178 & 50 & 8.2 & 14 & 1.71 \\
\hline 179 & 54 & 0.9 & 2.6 & 2.89 \\
\hline 180 & 44 & 2.7 & 15.9 & 5.89 \\
\hline 181 & 54 & 4.8 & 21 & 4.37 \\
\hline 182 & 45 & 5.3 & 14.6 & 2.75 \\
\hline 183 & 36 & 4.7 & 18.44 & 3.92 \\
\hline 184 & 28 & 8.6 & 28.9 & 3.36 \\
\hline 185 & 36 & 2 & 8 & 4 \\
\hline 186 & 81 & 3.9 & 16.3 & 4.17 \\
\hline Control-1 & & 2.03 & 65 & 32.02 \\
\hline Control-2 & & 15.17 & 67.1 & 4.42 \\
\hline
\end{tabular}

Table 1C: Testosterone and SHBG concentration in 186 women.

Tables 1A-1C shows results of total and free testosterone of 186 women in Eket community of Akwa Ibom state.

\section{Discussion}

In trying to interpret the laboratory results on serum testosterone, free testosterone, and sex hormone binding globulin concentration, it was observed that most laboratories establish its reference ranges that compensate for calibration errors in equipment or for their methods. What seems frustrating is that, instead of adjusting the results and rendering them in some standardized fashion, each laboratory, establishes an adjusted reference range. This makes direct comparisons of results from one laboratory with another impossible, while exemplified results are shown in Figures 1 and 2. Thus, this result will be interpreted without necessarily comparing with existing data. Testosterone is an excellent target for cancer therapy because it has been shown to be an effective target for breast and prostate cancer treatment due to its expression in the majority of breast cancer [13]. A clearer understanding of the mechanism of testosterone signaling in the breast is yet to be revealed, but with continued research efforts, there is hope that viable breast cancer therapies will be exploited through testosterones signaling. Excess amounts of testosterone can pose a problem, resulting in such "virilizing effects" as acne, hirsutism (excess hair growth in "inappropriate" places, like the chin or upper lip) and thinning of hair on the head (balding). About 10 percent of women with high levels of free testosterone have polycystic ovary syndrome (PCOS), characterized by irregular or absence of menstrual periods, infertility, blood sugar disorders (pre-diabetes and type 2 diabetes) [14]. Most women with PCOS are overweight or obese, though small percentages have a normal body weight. When such women are left untreated, high levels of testosterone, regardless of whether a woman has PCOS or not, are associated with serious health consequences, such as insulin resistance and diabetes, high cholesterol, high blood pressure and heart disease [15]. In addition to PCOS, other causes of high testosterone levels - hyperandrogenism include congenital adrenal hyperplasia (a genetic disorder affecting the adrenal gland that afflicts about one in 10,000 to one in 18,000 individuals, where about half are women) and other adrenal abnormalities, and ovarian or adrenal tumours [16]. Medications such as anabolic steroids, occasionally abused by bodybuilders and other athletes for performance enhancement, can also cause hyperandrogenic symptoms [16].

Tables 1A-1C present the testosterone concentration in women. The result showed that 38 women have elevated free testosterone concentration above the normal range $(2.03-15.17 \mathrm{ng} / \mathrm{ml})$. This accounted for $20 \%$ of $38 / 186$ women population with testosterone elevation. Investigations have shown that excessive amount of male 
hormone production by the ovary is the main feature of the polycystic ovarian syndrome (PCOS), which leads to many of the findings that women with PCOS experience [17]. According to the Center for Young Women's Health, PCOS results in many tiny cysts or bumps inside the ovaries hyperprolactinemia can result in abdominal pain and irregular periods. PCOS is caused by hormones in the brain and ovaries, which act as chemical messengers that inform the body when to ovulate, menstruate and grow hair among other activities. The Center also reported that skin cells and hair follicles are extremely sensitive to the slightest increase in female testosterone levels, and this can cause acne and facial hair [18]. A history of preeclampsia an average of 17 years earlier appears to be associated with elevated levels of testosterone, which may contribute to the increased risk of vascular morbidity in such women [19].

The concentration of testosterone and SHBG were interpolated by Spline and Lowess method using the Spline Curve as provided in Figures 1 and 2. Also, other factors that may influence this investigation include sampling time, which is an important consideration when interpreting serum testosterone. The result showed that intra-individual variation in testosterone levels of approximately $10 \%$ is observed when samples are collected from the same individual at the same time of the day over several days. Conditions that increase SHBG include aging, hyperthyroidism and hepatic cirrhosis, or that which decrease SHBG include obesity, diabetes mellitus, and glucocorticoid usage can affect the bioavailability of testosterone.

Low testosterone levels can as well be a problem, producing effects such as low libido, fatigue, decreased the sense of well-being and increased susceptibility to bone loss, osteoporosis, and fractures [18]. Symptoms such as flagging desire and general malaise have different causes, and testosterone deficiency - hyperandrogenism is usually not undiagnosed. Low androgen levels may affect women at any age but occur during the transition to menopause, or perimenopause. Testosterone levels start dropping in a woman's above twenty years, and by the time she reaches menopause, testosterone has declined $50 \%$. Further declines in ten years following menopause indicate everdecreasing ovarian function [15]. For many women, the effects of this further testosterone decline include aggravation of hot flashes and accelerated bone loss. These effects may not become obvious until the women are in their late 50 s or early 60 s.

The increase in SHBG with age means that older women may have normal total testosterone levels, even if they are hypogonadal, as they have low levels of free or bio-available testosterone (TT) [20]. Conversely, obesity decreases SHBG and TT, even when the bioavailable fraction may be normal [21]. Low free and bioavailable testosterone concentrations in the normal range are associated with diabetes, independent of adiposity [22]. Low concentrations are found in myxoedema, hyperprolactinemia, and syndromes of excessive androgen activity. Measurement of SHBG is useful in evaluating mild disorders of testosterone metabolism and enables identification of women with hirsutism, who are likely to respond to estrogen therapy. The ratio of SHBG to testosterone is also known as the Free Androgen Index (FAI) or the Free Testosterone Index (FTI). This ratio correlates with both measured and calculated values of free testosterone and helps to discriminate subjects with excessive testosterone activity from normal individuals [23]. Metabolic clearance of SHBG is biphasic, with a fast initial distribution from vascular compartment into extracellular space (half-life of a few hours), followed by a slower degradation phase (half-life of several days). SHBG binds sex steroids with high affinity (KD approximately 10[-10] M), dihydrotestosterone (DHT) $\geq$ testosterone ( $T$ ) $\geq$ estrone/estradiol (E) NCCLS (2002). Although each monomeric subunit contains 1 steroid binding site, the dimer tends to bind only a single sex-steroid molecule. The main function of SHBG is sex-steroid transport within the bloodstream and to extravascular target tissues [24]. SHBG also plays a key role in regulating bioavailable sex-steroid concentrations through the competition of sex steroids for available binding sites and fluctuations in SHBG concentrations [25]. Because of the higher affinity of SHBG for DHT and TT, SHBG have profound effects on the balance between bioavailable testosterone and estrogens.

\section{Conclusion}

The evidence for adverse reproductive outcomes (infertility, cancers, and malformations) from hormonal imbalances is strong, and there is mounting evidence for effects on other endocrine markers, including thyroid, neuroendocrine, obesity and metabolism, and insulin and glucose homeostasis. The precautionary principle is to enhancing hormonal and reproductive health and should be used to inform decisions about health status and risk from, potential hormonal imbalances.

\section{Acknowledgment}

We sincerely appreciate the efforts of the Head of Department of Medical Laboratory Science and Hematology Unit, Mr. Akaka Christopher who collected the blood samples from donors and Miss Ada who separated the serum. We thank Dr. Emmanuel Nna of Safety Pathology Laboratory, who did the statistical analysis.

\section{References}

1. Labrie F (2006) Dehydroepiandrosterone, androgens and the mammary gland. Gynecol Endocrinol 22: 118-130.

2. Lobo RA (2001) Androgens in postmenopausal women: production, possible role, and replacement options. Obstet Gynecol Surv 56: 361-376.

3. Dimitrakakis C, Bondy C (2009) Androgens and the breast. Breast Cancer Res 11: 212.

4. Dimitrakakis C, Glaser RL, Zava DT, Tsigginou A, Marinopoulos S, et al. (2009) The protective role of androgens: salivary hormone levels in newly diagnosed breast cancer patients. 26th Annual Miami Breast Cancer Conference, Miami, Florida.

5. Key TJ, Appleby PN, Reeves GK, Roddam A, Dorgan JF, et al. (2003) Body mass index, serum sex hormones, and breast cancer risk in postmenopausal women. J Natl Cancer Inst 95: 1218-1226.

6. Schmitt M, Klinga K, Schnarr B, Morfin R, Mayer D (2001) Dehydroepiandrosterone stimulates proliferation and gene expression in MCF-7 cells after conversion to estradiol. Mol Cell Endocrinol 173: 1-13.

7. Vanderschueren D, Vandenput L, Boonen S, Lindberg MK, Bouillon R, et al. (2003) Androgens and bone. Endocr Rev 25: 389-425.

8. Beattie MS, Costantino JP, Cummings SR, Wickerham DL, Vogel VG, et al. (2006) Endogenous sex hormones, breast cancer risk, and tamoxifen response: an ancillary study in the NSABP Breast Cancer Prevention Trial (P-1). J Natl Cancer Inst 98: 110-115.

9. Adly L, Hill D, Sherman ME, Sturgeon SR, Fears T, et al. (2006) Serum concentrations of estrogens, sex hormone-binding globulin, and androgens and risk of breast cancer in postmenopausal women. Int J Cancer 119: 2402-2407.

10. Somboonporn W, Davis SR (2004) Testosterone effects on the breast: implications for testosterone therapy for women. Endocr Rev 25: 374-388.

11. Conner P (2007) Breast response to menopausal hormone therapy aspects on proliferation, apoptosis and mammographic density. Ann Med 39: $28-41$. 
Citation: Okpashi VE, Obi BC, Okagu I, Okoroafor PO (2018) Epidemiological Assessment of Testosterone Levels in Women Population: A Factorial Analysis of Cell Proliferation. Biol Med (Aligarh) 10: 440. doi:10.4172/0974-8369.1000440

Page 8 of 8

12. http://www.raosoft.com/samplesize.html

13. Garay JP, Park BH (2012) Androgen receptor as a targeted therapy for breast cancer. Am J Cancer Res 2: 434-445.

14. Lerchbaum E, Schwetz V, Rabe T, Giuliani A, Obermayer-Pietsch B (2014) Hyperandrogenemia in Polycystic Ovary Syndrome: Exploration of the Role of Free Testosterone and Androstenedione in Metabolic Phenotype. PLoS ONE 9: e108263.

15. Bann D, Wu FC, Keevil B, Lashen H, Adams J, et al. (2015) Changes in Testosterone Related to Body Composition in Late Midlife: Findings from the 1946 British Birth Cohort Study. Obesity (Silver Spring) 23: 1486-1492.

16. Hofling M, Hirschberg AL, Skoog L, Tani E, Hagerstrom T, et al. (2007) Testosterone inhibits estrogen/progestogen induced breast cell proliferation in postmenopausal women. Menopause 14: 183-190.

17. Norman RJ, Noakes M, Wu R, Davies MJ, Moran L, et al. (2004) Improving reproductive performance in overweight/obese women with effective weight management. Hum Reprod Update 10: 267-280.

18. MacDonald AA, Herbison GP, Showell M, Farquhar CM (2010) The impact of body mass index on semen parameters and reproductive hormones in human males: a systematic review with meta-analysis. Hum Reprod Update 16: 293-311.
19. Sosa-Ferrera Z, Mahugo-Santana C, Santana-Rodríguez JJ (2013) Analytical Methodologies for the Determination of Endocrine Disrupting Compounds in Biological and Environmental Samples. Biomed Res Int.

20. Brambilla DJ, Matsumoto AM, Araujo AB, McKinlay JB (2009) The effect of diurnal variation on clinical measurement of serum testosterone and other sex hormone levels in men. J Clin Endocrinol Metab 94: 907-913.

21. Herzog AG, Levesque LA (1992) Testosterone, free testosterone, nonsex hormone binding globulin, and free androgen index: which testosterone measurement is most relevant to reproduction and sexual function in men with epilepsy? Arch Neurol 49: 133-135.

22. Selvin E, Feinleib M, Zhang L, Rohrmann S, Rifai N, et al. (2007) Androgens and diabetes, in men. Diabetes Care 30: 234-238.

23. Braunstein GD (2002) Androgen insufficiency in women: summary of critical issues. Fertil Steril 77: S94-99

24. WHO (2004) Guidelines for drinking-water quality. WHO, Geneva, Switzerland.

25. Zoeller R, Thomas TR, Brown LL, Doan AC, Gore NE, et al. (2012) Endocrine-disrupting chemicals and public health protection: A statement of principles from the endocrine society. Endocrinology 153: 4097-4110. 